\begin{tabular}{c} 
International Journal of Engineering \& Technology, $7(4)(2018) 2525-2527$ \\
International Journal of Engineering \& Technology \\
SPC \\
$\begin{array}{c}\text { Website: } \text { www.sciencepubco.com/index.php/IJET } \\
\text { doi: } 10.14419 / \text { ijet. } v 744.14058 \\
\text { Research paper }\end{array}$ \\
\hline
\end{tabular}

\title{
Design of CPW antenna for network applications
}

\author{
R. Sanmugasundaram ${ }^{1} *$, D. Dileepan ${ }^{1}$, S. Natarajan ${ }^{1}$ \\ ${ }^{1}$ Vel Tech Rangarajan Dr. Sagunthala R\&D Institute of Science and Technology, Chennai, India \\ *Corresponding author E-mail: rsanmu88@gmail.com
}

\begin{abstract}
The novel CPW antenna design consists of monopole, which can used for High speed wide area or local area corporate networks and Video \& CCTV surveillance networks and Long-range Rural connectivity. This antenna has been designed with design size parameters of $59.5(\mathrm{~L}) \times 30(\mathrm{~W}) \times 1.6-(\mathrm{H}) \mathrm{mm} 2$, the dielectric constant of FR4 substrate is 4.4, and loss tangent of 0.002 is used. The resonant frequency range of this proposed antenna is $5.85-6.6 \mathrm{GHz}$ with return loss above of $-10 \mathrm{~dB}$ achieved. The peak gain of this antenna is $5.5 \mathrm{dBi}$ and in addition the S, Z-parameters, VSWR, 2D \& 3D radiation pattern are also derived. Good results are achieved after simulation.
\end{abstract}

Keywords: Micro Strip, WLAN; Surveillance Networks; Wireless Applications Etc.

\section{Introduction}

Circularly polarized (CP) antennas are more applicable in numerous communication systems (GPS, RFID, WLAN and WiMAX). Circularly polarized is having more advantages when compared to linearly polarized (LP) such as tactlessness towards equipment's orientation, resistance to mitigated multipath losses[1]-[2]. The advantages of monopole antennas are low profile, cheap cost, broader band operating bandwidths and easy structure. A simple printed three slot antenna structure having the arms with lengths is reported to the $\mathrm{CP}$ operation[3]-[4]. The CP operation and principle may be achieved by generating TM11 modes that are $90^{\circ}$ phase. Coplanar waveguide is one of the feeding techniques to radiate the antenna; the power supply is given through the feeding line[5]-[7].

\section{Antenna design parameters}

The CPW-fed antenna with gap and non symmetric ground plane is designed as shown in Fig.1. The antenna is printed on top of the FR4 substrate. The proposed antenna is having er of 1.06 and $\tan \delta$ is 0.002 . The three slot of size $26 \times 22 \mathrm{~mm}$ is feed with a $50 \Omega \mathrm{CPW}$ feeding line of width $1.3 \mathrm{~mm}$ and two equal gap of width $0.4 \mathrm{~mm}$ is produced. From the structure, it is observe that it is having asymmetric ground plane. An irregular ground plane is used to stimulate CP operation and also to get better impedance matching [8]-[9]. The surface current distributions will explain the $\mathrm{CP}$ mechanism.

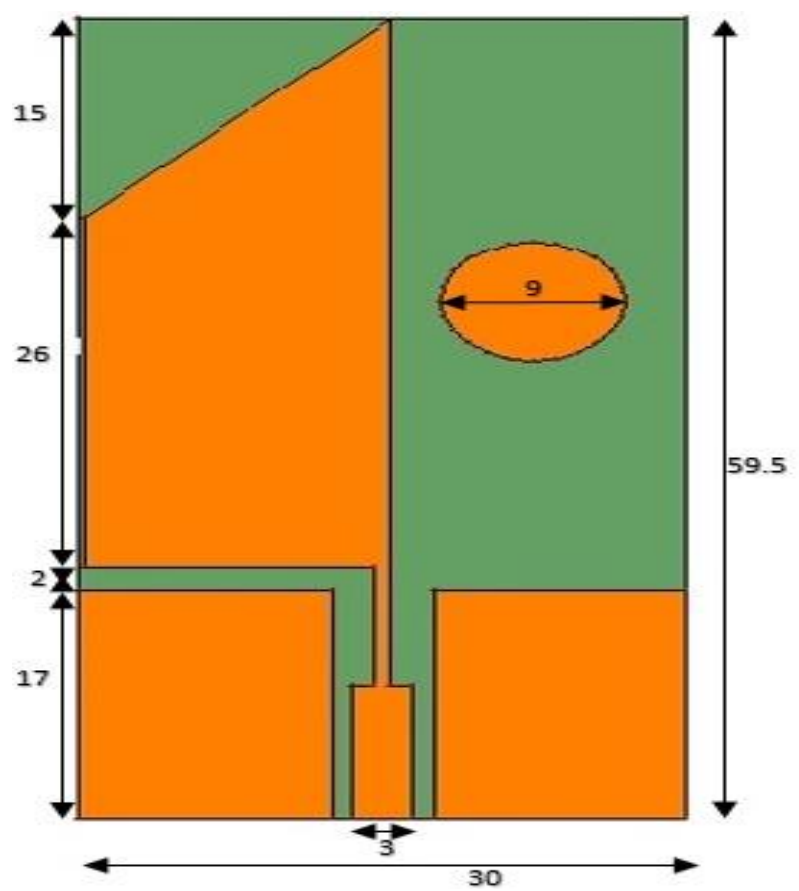

Fig. 1: Geometrical View of Proposed Antenna (Units In Mm).

$\mathrm{CP}$ radiation is observed by employing the irregular ground plane feed method. The three slots inside square with gaps give minimum return loss value at desired frequency range [10]. The coupled effect between three slots and the square, the CP radiation is radiated at $6.4 \mathrm{GHz}$.

For this antenna, it is having better impedance matching and narrow bandwidth. Different parameters have to be studied and to get the optimized dimensions of proposed antenna. The parameters includes S, Z- parameters, VSWR, azimuth and elevation patterns, gain(vs)frequency, 3D radiation pattern etc. 


\section{Results and discussion}

The proposed CPW fed Monopole antenna is simulated using Mentor Graphics IE3D simulator version14.0. The optimized antenna design with the dimensions and its performance was validated. The S-parameters or characteristics of Return loss of the proposed antenna is shown in Fig.2. Return loss of an antenna should be less than $-10 \mathrm{~dB}$. The proposed antenna resonant frequency is $5.85 \mathrm{GHz}$ to $6.6 \mathrm{GHz}$ with the return loss less than $10 \mathrm{~dB}$. Higher the return loss lower will be interferences between the signals i.e., reflection is small, so that performance will be better. The maximum return loss around $-24 \mathrm{~dB}$ at $6.4 \mathrm{GHz}$ frequency. The VSWR characteristic for the proposed antenna is shows $1: 2$ ratio VSWR at $6.4 \mathrm{GHz}$ in the Fig. 3 .

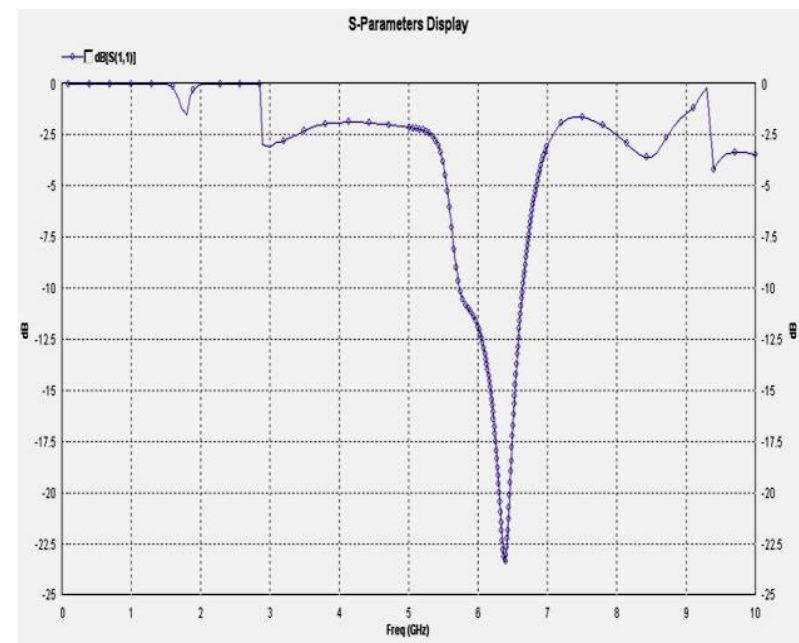

Fig .2: Return Loss Characteristics.

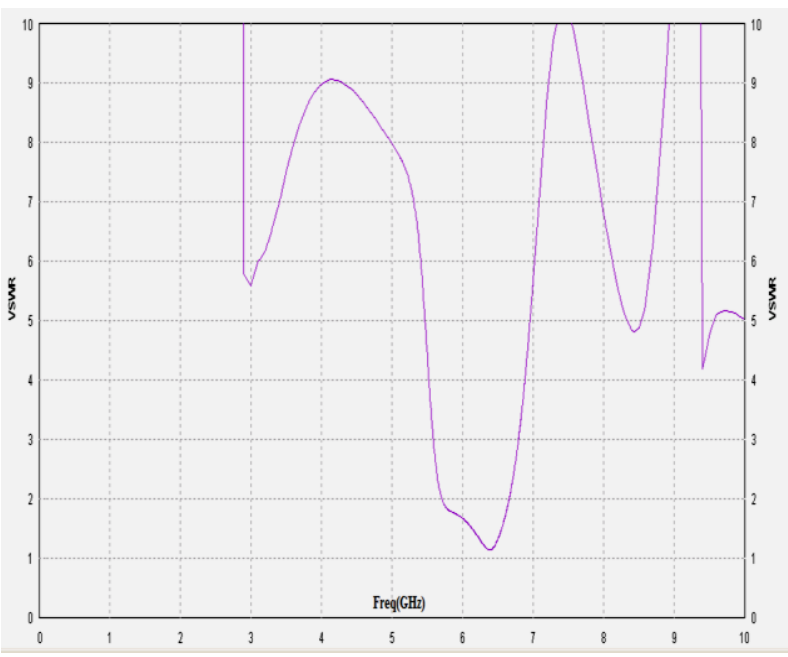

Fig. 3: VSWR Characteristics.

The proposed three slots antenna shows better impedance matching around $50 \Omega$ at $6.4 \mathrm{GHz}$ as shown in Fig.4. The surface current distribution and the radiation pattern at the resonant frequency are shown in Fig.5. Total gain verses frequency plot is exhibited in Fig.6 and the gain of the antenna is $5.5 \mathrm{dBi}$ at resonant frequency of $6.4 \mathrm{GHz}$. The proposed antenna shows both antenna efficiency and radiation efficiency can be observed.

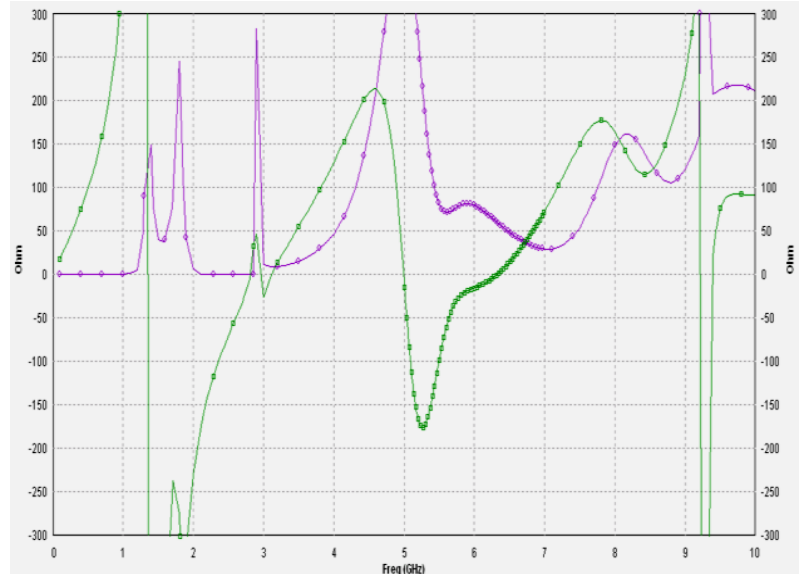

Fig. 4: Impedance Characteristics.

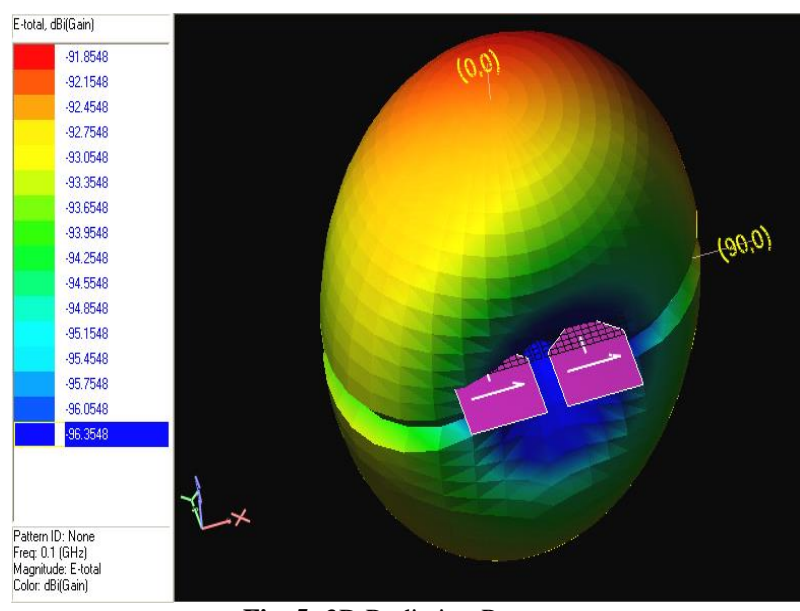

Fig. 5: 3D Radiation Pattern.

Fig.7 and Fig. 8 are showing the simulated radiation patterns for both elevation and azimuth pattern. A relatively good agreement between the E-Plane and H-Plane results can be observed. The minor discrepancy can be mostly attributed to the edges of the conductor in simulation.

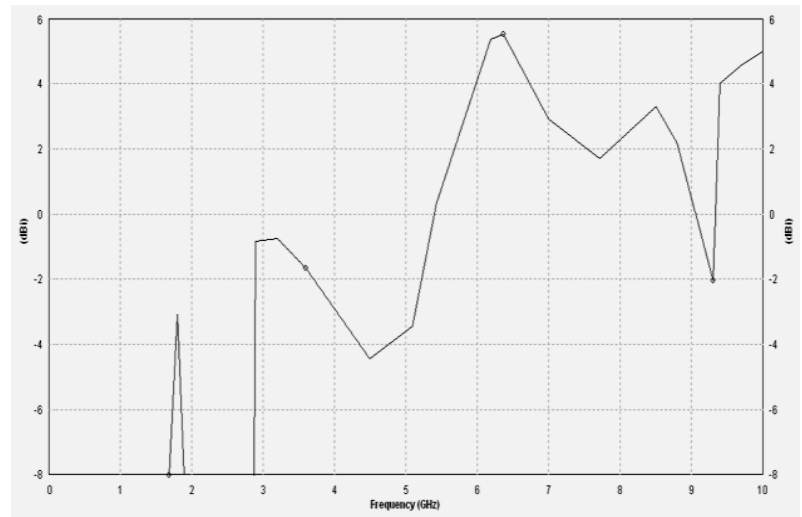

Fig. 6: Gain vs Frequency. 


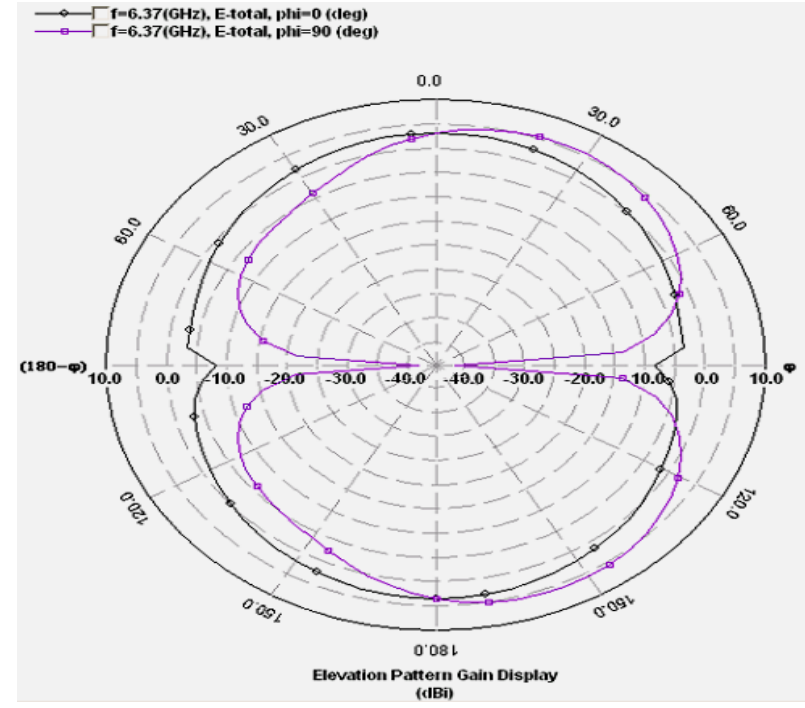

Fig. 7: Elevation Pattern.

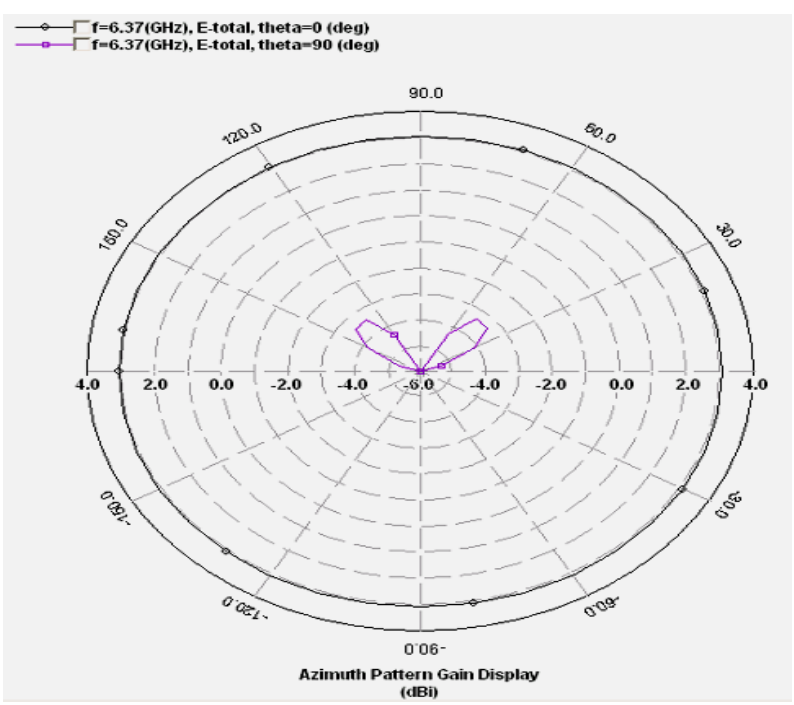

Fig. 8: Azimuth Pattern.

\section{Conclusion}

A small size coplanar waveguide fed monopole antenna is designed and the results are discussed for Industrial Scientific and Medical Band applications. The Monopole antenna is operating the frequency ranging from $5.85 \mathrm{GHz}$ to $6.6 \mathrm{GHz}$. The proposed novel antenna yield miniaturization, good lower return loss $(-24 \mathrm{~dB})$,

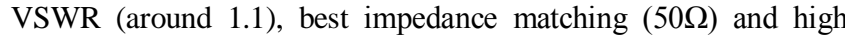
gain $(5.5 \mathrm{dBi})$ compared to over other conventional antennas. The observed radiation patterns are stable within the frequency band. It is very easy to design and fabricate.

\section{References}

[1] S X Ta, I Park, R W Ziolkowski, "Broadband Electrically Small Circularly Polarized Directive Antenna" IEEE Access, Vol.5, PP.14657 - 14663, 2017

[2] S. Ashok Kumar and T. Shanmuganantham, "Design and Analysis of Implantable CPW Fed Bowtie Antenna for ISM Band Applications" International Journal of Electronics and Communication, Elsevier Publications, vol.68, 2/2014, pp.158-165.

[3] Ming-Chun Tang; Xiaoming Chen; Mei Li; Richard W. Ziolkowski, "A Bandwidth-Enhanced, Compact, Single-Feed, Low-Profile, Multilayered, Circularly Polarized Patch Antenna" IEEE Ant. \& Wireless Prop. Lett. Vol.16, PP. 2258 - 2261, 2017.

[4] S. Ashok Kumar and T. Shanmuganantham, "Analysis and Design of Implantable Z-Monopole Antennas at $2.45 \mathrm{GHz}$ ISM Band for Biomedical Applications" Microwave and Optical Technology Let- ters, Wiley and Blackwell, US. Vol.57, No.2, pp. 468-473, Feb 2015. https://doi.org/10.1002/mop.28870.

[5] Sara Salem Hesari Jens Bornemann, "Wideband Circularly Polarized Substrate Integrated Waveguide Endfire Antenna System with High Gain" IEEE Antennas and Wireless Propagation Letters, Vol.16, PP.2262 - 2265, 2017.

[6] S. A Kumar and T. Shanmuganantham, "CPW Fed Implantable ZMonopole Antennas for ISM Band Biomedical Applications", International Journal of Microwave and Wireless Technologies, Cambridge University, UK. Vol.7 (5) pp. 529-533, Oct 2015. https://doi.org/10.1017/S1759078714000725.

[7] S. Ashok Kumar and T. Shanmuganantham, "CPW fed Monopole Implantable Antenna for $2.45 \mathrm{GHz}$ ISM Band Applications" Int. J. of Elect. Letters, Taylor \& Francis, UK. vol.3 (3), pp. 152-159, 2015.

[8] S. A Kumar and Thangavelu S, "Design and Analysis of Implantable CPW fed X-Monopole antenna for ISM Band Applications" Telemedicine and e- Health, vol.20 (3), 2014.

[9] C F Zhou, S W Cheung, "A Wideband CP Crossed Slot Antenna Using 1- $\lambda$ Resonant Mode With Single Feeding" IEEE Trans. on Ant. \& Prop., Vol.65, Issue: 8 , PP.4268 - 4273, 2017.

[10] S A Kumar, Shanmuganantham T, "Design and Development of Implantable CPW fed Monopole U Slot Antenna at $2.45 \mathrm{GHz}$ ISM Band for Biomedical Applications" Microw. In addition, Opt. Tech. Lett., Wiley, vol. 57(7), 2015. 